Bond University

Research Repository

\title{
Multimodal Learning in Health Sciences and Medicine: Merging Technologies to Enhance Student Learning and Communication
}

Moro, Christian; Smith, Jessica; Stromberga, Zane

Published in:

Biomedical Visualisation

DOI:

10.1007/978-3-030-31904-5_5

Licence:

Other

Link to output in Bond University research repository.

Recommended citation(APA):

Moro, C., Smith, J., \& Stromberga, Z. (2019). Multimodal Learning in Health Sciences and Medicine: Merging Technologies to Enhance Student Learning and Communication. In P. M. Rea (Ed.), Biomedical Visualisation (Vol. 5, pp. 71-78). (Advances in Experimental Medicine and Biology; Vol. 1205). Springer.

https://doi.org/10.1007/978-3-030-31904-5_5

\section{General rights}

Copyright and moral rights for the publications made accessible in the public portal are retained by the authors and/or other copyright owners and it is a condition of accessing publications that users recognise and abide by the legal requirements associated with these rights.

For more information, or if you believe that this document breaches copyright, please contact the Bond University research repository coordinator. 


\title{
Multimodal learning in health sciences and medicine: Merging technologies to enhance student learning and communication
}

Christian Moro, Jessica Smith, and Zane Stromberga

\section{Affiliations}

- Associate Professor Christian Moro. Faculty of Health Sciences and Medicine, Bond University Gold Coast QLD 4229. cmoro@bond.edu.au.

- Jessica Smith. Faculty of Health Sciences and Medicine, Bond University Gold Coast QLD 4229.jesssmit@bond.edu.au.

- Zane Stromberga. Faculty of Health Sciences and Medicine, Bond University Gold Coast QLD 4229. zstrombe@bond.edu.au.

\begin{abstract}
Advances in consumer-level educational technologies show great promise for enhancing the learning experiences of students in health and medicine. There are particular benefits towards using combinations of devices and technologies when demonstrating challenging concepts. These include using augmented reality-enabled devices enriched with accompanying 3D printed models, or virtual reality sessions coupled with online quizzes or revision activities alongside. Tablet applications can also be integrated while students concurrently engage in desktop-based online learning. This mixing and merging of different technologies can allow educators to focus on the strengths of each device, while mitigating limitations arising from a single mode's stand-alone use. This chapter describes a series of options to integrate multiple digital modes when educating health and medical students using technology. It also presents the case for health profession program graduates to be trained in teaching using technology, as their future will careers can be enhanced by an ability to educate effectively, as well as the potentials when incorporating serious games into a health curriculum. With the dynamic and ever-changing nature of health and medical education, educators can find great benefits when introducing multi-model digital learning into their respective courses.
\end{abstract}

Keywords: multimodal education, mixed-mode learning, augmented reality, educational technology, 3D printing, medical education, serious games. 
Technology is being introduced in universities at ever-increasing rates. New students are arriving at tertiary institutions from schools where combining two or more modes was common in daily curriculum (Mills 2010), and as such, would expect this same interactivity in a modern university course. Making e-books, videos, animations, blogs, web pages, and digital games are the new ways of demonstrating literacy that involve clever combinations of these modes. In digital platforms, text is most often accompanied illustrations, interactivity, pop-ups, hyperlinks, and audio files to create meaning that extends beyond the possibilities of solely-written works such as essays (Unsworth 2001). This is increasingly becoming a core component of school education, where more than 200 learning outcomes in the Australian School Curriculum address this type of literacy, right from foundation (prep) to year 12. Nearly half (44\%) of current jobs are at high risk of being digitally disrupted in the next 20 years (Moro and Mills 2019), and as such, incorporating technology into university curriculum is not only beneficial to learning, but can also be vital to students ability to work effectively in their future careers. The incorporation of technology into teaching practices at universities has also resulted in academics moving away from the traditional didactic-style lecture and into more digitally-enhanced group-based (Moro and McLean 2017), self-directed (Murad et al. 2010) or online modes of learning (Clark and Mayer 2016). However, the next step is to integrate multiple forms of technology in learning. This can involve mixing 3D printing with cadaveric labs, or textbooks with smartphone or tablet applications. The merging of multiple devices allows educators to engage using the strength of various modes, which can be particularly beneficial in disciplines such as anatomy or general health care education (Estai and Bunt 2016).

Mobile devices, such as smartphones and tablets, have the potential to aid teaching in health sciences and medicine. These devices can not only be used for communication and entertainment purposes but also aid in providing easy access to a wide variety of electronic resources to support learning, such as interactive 3D models. Pimmer et al. (2016) review of past studies utilising mobile devices in higher education revealed that health and medicine were the dominant areas in which mobile learning was used. Furthermore, the authors showed that the multimodal representation of study material helped facilitate personalised and more frequent study practice and aid in improved learning outcomes. These conclusions were also supported in Klímová (2018) review of 10 randomised controlled trials of the use of mobile learning in healthcare professional and medicine education, where the authors determined mobile learning as a beneficial tool in the acquisition of new knowledge and skills that were perceived by the students as an appropriate supplement to traditional learning tools.

There are several other interactive technologies capable of displaying high-quality 3D models that can be incorporated into modern health sciences and medicine curricula. For example, when using virtual 
reality (VR) devices (Figure 1, left), the user's senses (sight, hearing, and motion) are fully immersed in a synthetic environment that mimics the properties of the real world through high resolution, high refresh rate head-mounted displays, stereo headphones and motion-tracking systems (Kuehn 2018; Moro et al. 2017a; Moro et al. 2017b). This technology has a multitude of applications and has previously been used to enhance learning and skill acquisition across different disciplines in education (Jensen and Konradsen 2018), aid patient rehabilitation with cognitive impairment (De Luca et al. 2018) and assist in anxiety reduction (Camara and Hicks 2019). A more accessible technology to the general consumer is augmented reality (AR) which utilises a camera and screen (i.e. smartphone or tablet) to display 3D models superimposed into the real-world. The user is then able to interact with both the real and virtual elements of their surrounding environment (Birt et al. 2018). Due to its easy accessibility, this technology has been widely used to assist in STEM education (Ibáñez and Delgado-Kloos 2018), online retailing (Bonetti et al. 2018), gaming experience (Hamari et al. 2019) and tourism (tom Dieck and Jung 2018) to name a few. Lastly, mixed reality (MR) is a merging of AR and VR environments, with real and virtual words superimposed through head-mounted displays allowing for life-like renders of anatomy and physiology in real-time using devices like Microsoft HoloLens 2 (Figure 1, right). This mixed reality technology is still in development stages and not yet widely available and affordable for the general consumer.
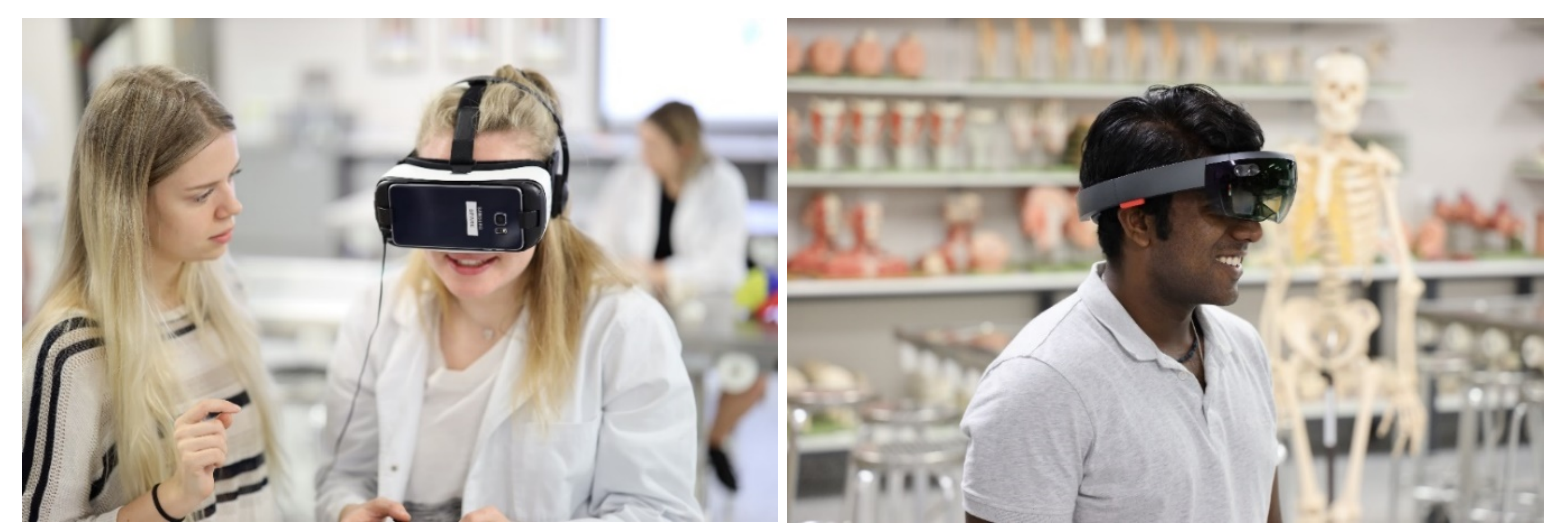

Figure 1: Left: An educator assists a student utilising a Samsung Gear VR device for 3D visualisations.

Right: A Biomedical Science student utilising the Microsoft HoloLens to augment available 3D skeleton models by adding muscle layers over the top.

\section{Merging printed text and hand-held interactive $3 D$ visualisation devices}

Using traditional methods of learning, such as attending didactic lectures and using printed resources, has caused an over-reliance on simple memorisation as the predominant study tactic (Cai et al. 2018), which is classified as the lowest order of learning by Bloom's taxonomy (Krathwohl 2002). Comprehensive understanding of a concept is considered as the highest order of learning in Bloom's taxonomy, which extends beyond simply recognising a structure and remembering its clinical 
significance. Science and medical students often experience difficulty obtaining spatial understanding of three-dimensional (3D) structures from two-dimensional (2D) illustrations, such as those in found in science textbooks (Berney et al. 2015). By using these traditional methods of learning, students are required to mentally manipulate and rotate static, two-dimensional illustrations. While textbook learning resources provide invaluable factual knowledge about different scientific concepts, students who have difficulties to mentally perceiving and rotating three-dimensional models consequently perform worse in tests evaluating spatial knowledge. However, the interactive 3D applications alone do not provide the depth necessary to fully grasp the concepts surrounding the structure in question. Using printed text in conjunction with digital 3D visualisation methods may help learners acquire information and build mental representations of anatomical or physiological structures. Moreover, it will also provide an opportunity to adapt the education tools to the different types of learning styles. The use of this integrated teaching method in comparison to traditional methods of solely using 2D illustrations has previously been explored to some extent in the literature, mostly in teaching anatomy. Features can be visualised in 3D through a range of devices. This includes both Mixed and Virtual Reality, such as through the Microsoft HoloLens or the various Virtual Reality Devices (Figure 1).

Indeed, based on findings from a systematic review comparing various digital 3D visualisation methods to traditional teaching methods such as textbook learning concluded that not only medical students preferred to use 3D models over 2D images to learn anatomy, they also reported a higher knowledge gain and better results in knowledge-recall tests (Triepels et al. 2019). In an original research study, Nicholson et al. (2006) reconstructed a fully interactive 3D model of the middle and inner ear from a magnetic resonance imaging scan. In their study, medical students $(n=28)$ completed a tutorial on ear anatomy with an interactive 3D model, while the control group $(n=29)$ completed the tutorial without the exposure to the model. Based on knowledge quiz results, the $3 \mathrm{D}$ model group achieved a significantly higher mean score of $83 \%$ compared to $65 \%$ in the control group. In a more recent $\mathrm{Ng}$ et al. (2015) study, graduating medical students $(n=72)$ were randomised into two groups to study the anatomy of the middle ear: (1) 3D model and printed reading materials on the epitympanum anatomy and (2) printed reading materials with 2D illustrations of the epitympanum anatomy. The researchers found that using 3D models was not only the student preferred learning tool, but also 3D group fared significantly better in the anatomy quiz, achieving a mean score of $65.1 \%$ compared to $32.4 \%$ in the $2 \mathrm{D}$ group. Fields such as oncology or pharmacology are also becoming increasingly difficult to comprehend, with increasing numbers of medications and receptors discovered each year. As research into areas such as these continue to uncover additional actions of pharmaceuticals or receptor targets (Moro et al. 2016; Stromberga et al. 2019), the use of 3D devices can greatly assist the student when identifying the complex interactions. Thereby, combining the advantages of using printed materials together with interactive 3D visualisations presents as a promising approach to enhancing the learner's experience in health and medical education. 
In recent years, 3D printed specimens have become an alternative teaching tool in health sciences and medical education (Drake and Pawlina 2014). Prior to implementing this technology in teaching, it has been typically been used for preoperative assessment and presurgical planning in an industry setting (Faur et al. 2013). Before implementing this technology in teaching, it has typically been used for preoperative assessment and presurgical planning in an industry setting (Faur et al. 2013). These 3D printed models have been recognised as a great alternative to teaching involving cadavers, as the printed models are similar to cadaveric specimens and highly accurate when compared to the original specimen (McMenamin et al. 2014). Additionally, 3D printed models are more durable, are easy to reproduce in large quantities and are also more cost-effective than cadavers (Smith and Jones 2018). Using MRI and CT scans obtained from different patients and using 3D printing technology to reproduce these models can also help show anatomical variation that the students would not typically be exposed to if they solely used textbooks, anatomical atlases (either printed or 3D) or cadaveric specimens (Figure 2). While there are numerous advantages of incorporating this technology in teaching, it is also important to consider limitations. For example, these models are unable to accurately reflect the dynamic spatial relationships and movements between the anatomical structures, which are important in order for the students to understand functional anatomy. This limitation was addressed in Cai et al. (2018) study where the authors had 3D printed a dynamic knee joint simulator. The authors compared the traditional didactic lecture learning in medical students to using the knee joint simulator and found that students in the simulator group obtained significantly better results in a knowledge-based quiz when compared to the traditional learning group.

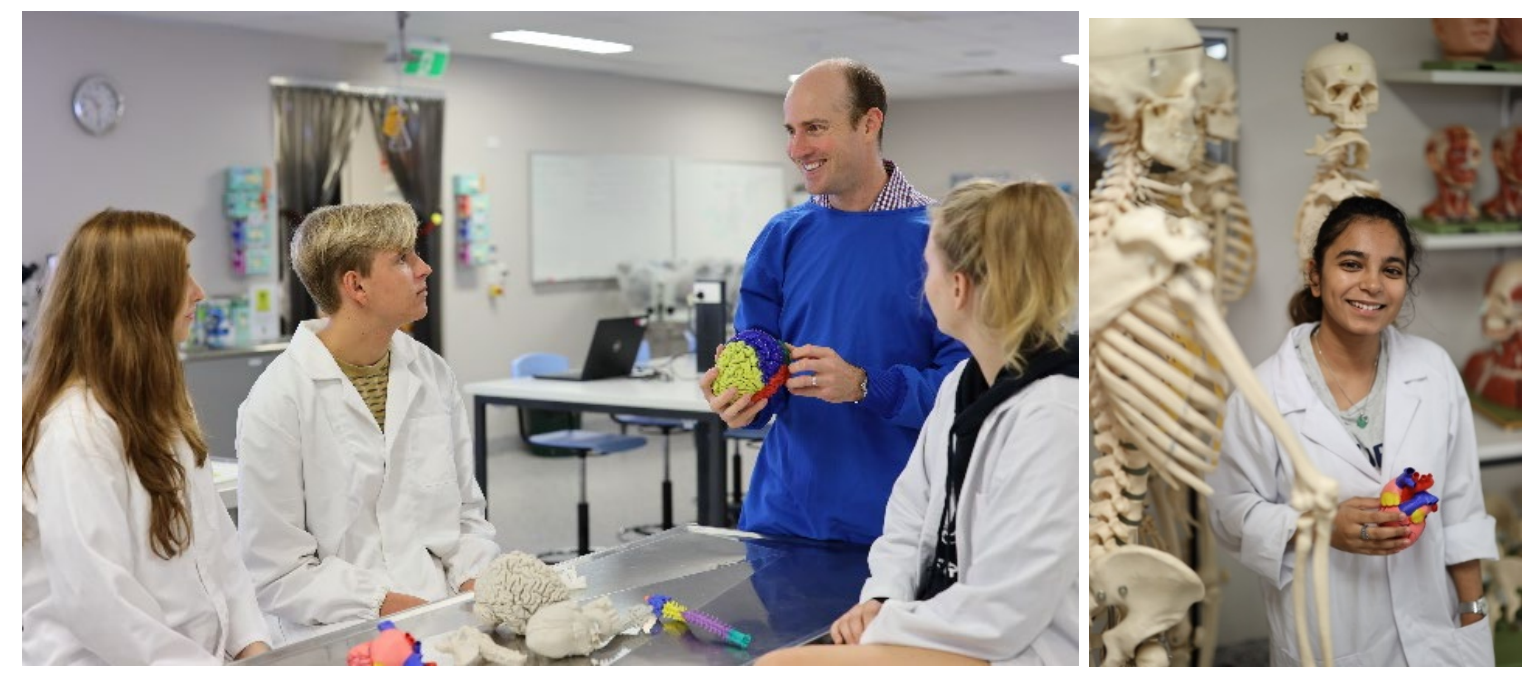

Figure 2: Left: Educators working with 3D printed models alongside cadaveric material to describe physiological concepts within a medical anatomical laboratory. Right: Students utilising 3D Printing 
to incorporate hearts, lungs and other anatomical structures into the traditional laboratory-based skeletons.

\section{Serious games and gamification in higher education}

The development in computer technology over the last two decades has given and the accessibility of the internet has given a rise in the use of games in a higher education setting. Serious games are interactive and entertaining digital software that serve an educational purpose. In health science and medicine, there is potential benefit to introducing gamified learning approaches, as long as they are supplementary in nature, and do not attempt to replace traditional medical teaching tools (Gorbanev et al. 2018). The number of serious games in health sciences and medicine is growing rapidly, and it the educators implementation strategies are vital to the success of these applications to learning. (Wang et al. 2016). Some games may also assist with surgical skills training, and other hands-on applied technical (Chon et al. 2019; Graafland et al. 2012). One appealing aspect of educators creating their own games, is the possibility of linking multiple modes into the one device. Text-based tablet applications, websites, visual stimulus, hyperlinks and interactive components can all be packaged in a way that can assist learning. This is evident in serious games for health science and medical anatomy and physiology education, such as the tertiary-level game, The King's Request: Anatomy and Physiology Revision Game (Figure 3). These types of completely free games, accessible to all students, are able to engage and excite student learning in traditionally dry or difficult subjects. These multimodal applications also bring the class content in-line with student's self-learning, where the majority of students consistently report using a variety of e-learning tools alongside the textbook (Wynter et al. 2019). There is also the additional benefit of training students up with games, which may in the future form part of the health careers. For example, serious games can be effectively utilised in the clinical environment for activities such as motor rehabilitation (Taut et al. 2017). 

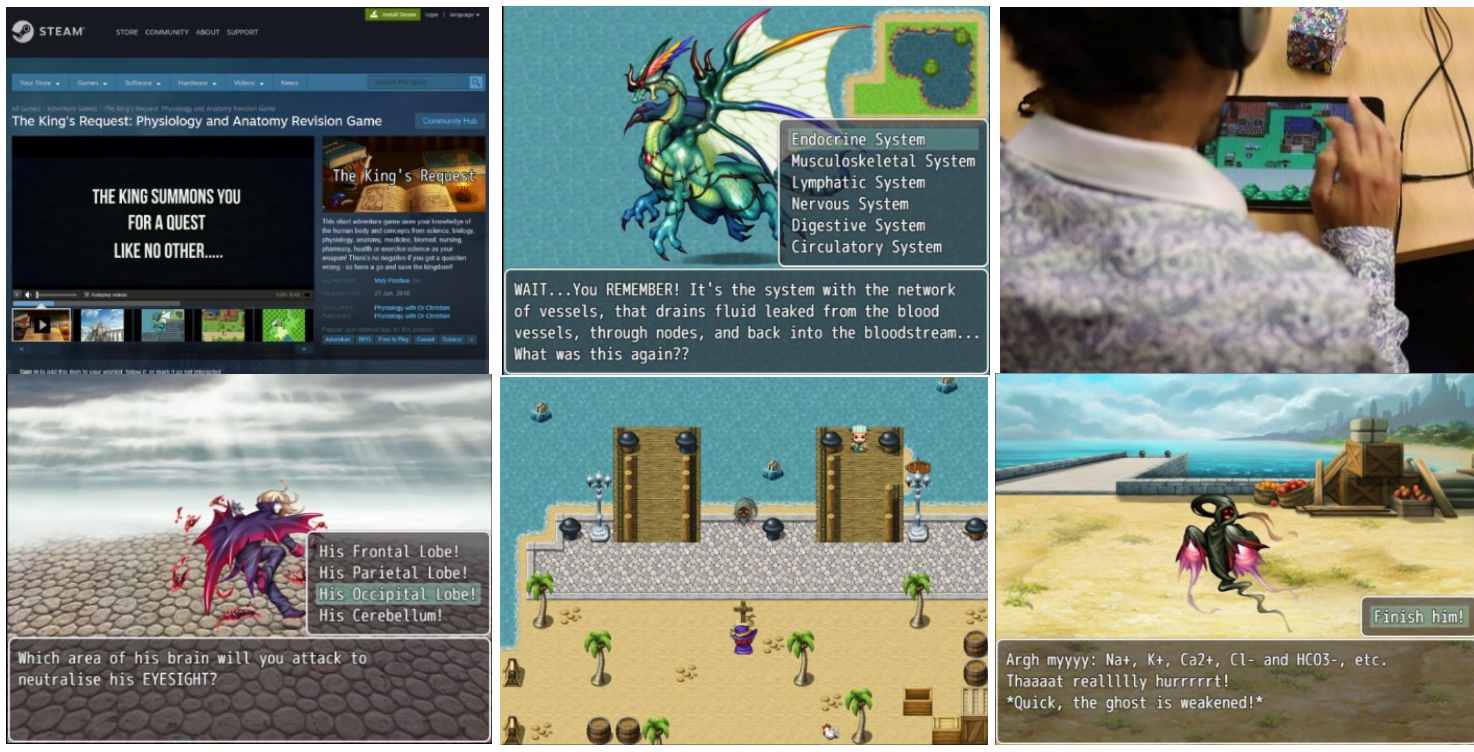

Figure 3: The King's Request: Anatomy and Physiology Revision Game. One of the available free games to engage students while revising health science content.

\section{Health communication: teaching health sciences and medical students to use technology in patient education}

One role of students graduating from health sciences and medicine will be educating their patients, clients and members of the community about their health. Most pursuits of the health system, whether it be physiotherapy, pharmacy, nursing, medicine or others involve the clinician explaining health concepts. As such, educating health science or medical students how to teach can be a great benefit to their future careers. This is particularly important when communicating with the community, where many people have difficulties with health literacy, or their ability to comprehend health information. Education in health is outlined as an essential constituent in the prevention of disease and promotion of health maintenance (Nutbeam 2000), where health professionals can increase patient health literacy through both formal and informal modes of education. Furthermore, epidemiological studies in the U.S. have revealed a link between health, socioeconomic status and educational attainment, where populations with lower educational achievement are more likely to have higher rates of morbidity and mortality as a result of chronic disease (Pamuk et al. 1998). Thus, by integrating training in how to educate others, and improve community health literacy into a tertiary health science curriculum, tertiary institutions can support students in their future careers.

Some challenges faced by modern graduates in health involve improving the health literacy of their patients and clients, many of whom may have irregular interactions with the health system, as well as greater responsibility for their treatment and care (Boice 1998). This type of additional expectation often leads medical students with concerns that they are not prepared for practice, and have not fully obtained all the required skills to be workplace-ready (Moro et al. 2019). Many teens with chronic 
illnesses, such as diabetes mellitus, use the internet to gather information relating to the management of their illness. As such, healthcare professionals need to be aware of what content is available online and expect this prior knowledge into their consultations. Young adults, in particular, can be difficult to educate, and this age group often feels as though they cannot comprehend information related to the maintenance of their health (Lindau et al. 2002). As such, universities need to anticipate these clinical difficulties and assist with promoting tertiary students' knowledge of health literacy (Ivanitskaya et al. 2006), the variability between population's education (van der Heide et al. 2013) and the quality of deliverance (Baker et al. 2000; Furnham et al. 2011). This further raises the question as to how health literacy can be improved, consistently and effectively, for young adults attending tertiary institutions. Many studies are now looking into the feasibility of augmented reality as an interactive educational intervention as there has been a recent shift from passive, teacher-centred learning towards active, student-centred learning (Moro et al. 2017a; Moro et al. 2017b).

\section{Conclusion}

The modern health science and medical educator is no longer restrained to one singular mode of teaching. Instead, multiple devices, modes, formats and technologies can be utilised simultaneously to enhance student engagement and learning as well as achieving a greater level of interactivity. Using multiple modes of content delivery allows the educator to maximise the strengths of each device, whilst minimising the limitations exhibited from relying on a single mode for learning. 


\section{References:}

Baker D, Gazmararian J, Sudano J, Patterson M (2000) The association between age and health literacy among elderly persons Journals of Gerontology B: Psychological Sciences and Social Sciences 55:S368-374

Berney S, Betrancourt M, Molinari G, Hoyek N (2015) How spatial abilities and dynamic visualizations interplay when learning functional anatomy with $3 \mathrm{D}$ anatomical models Anat Sci Educ 8:452-462 doi: 10.1002/ase.1524

Birt J, Stromberga Z, Cowling M, Moro C (2018) Mobile Mixed Reality for Experiential Learning and Simulation in Medical and Health Sciences Education Information 9:31

Boice M (1998) Chronic illness in adolescence Journal of Youth and Adolescence 33:927-939 Bonetti F, Warnaby G, Quinn L (2018) Augmented Reality and Virtual Reality in Physical and Online Retailing: A Review, Synthesis and Research Agenda. In: Jung T, tom Dieck MC (eds) Augmented Reality and Virtual Reality: Empowering Human, Place and Business. Springer International Publishing, Cham, pp 119-132. doi:10.1007/978-3-319-64027-3_9

Cai B, Rajendran K, Bay BH, Lee J, Yen CC (2018) The Effects of a Functional Threedimensional (3D) Printed Knee Joint Simulator in Improving Anatomical Spatial Knowledge Anat Sci Educ doi: 10.1002/ase.1847

Camara DR, Hicks RE (2019) Using virtual reality to reduce state anxiety and stress in university students: An experiment GSTF Journal of Psychology (JPsych) 4:15-15

Chon SH et al. (2019) Serious Games in Surgical Medical Education: A Virtual Emergency Department as a Tool for Teaching Clinical Reasoning to Medical Students JMIR serious games 7:e13028 doi: 10.2196/13028

Clark RC, Mayer RE (2016) E-learning and the science of instruction: Proven guidelines for consumers and designers of multimedia learning. John Wiley \& Sons,

De Luca R, Torrisi M, Piccolo A, Bonfiglio G, Tomasello P, Naro A, Calabrò RS (2018) Improving post-stroke cognitive and behavioral abnormalities by using virtual reality: A case report on a novel use of nirvana Applied Neuropsychology: Adult 25:581-585 doi: $10.1080 / 23279095.2017 .1338571$

Drake RL, Pawlina W (2014) An Addition to the neighborhood: 3D printed anatomy teaching resources Anatomical Sciences Education 7:419-419 doi: 10.1002/ase.1500

Estai M, Bunt S (2016) Best teaching practices in anatomy education: A critical review Annals of Anatomy - Anatomischer Anzeiger 208:151-157 doi: http://dx.doi.org/10.1016/j.aanat.2016.02.010 
Faur C, Crainic N, Sticlaru C, Oancea C (2013) Rapid prototyping technique in the preoperative planning for total hip arthroplasty with custom femoral components Wien Klin Wochenschr 125:144-149 doi: 10.1007/s00508-013-0335-1

Furnham A, Cook R, Martin N, Batey M (2011) Mental Health Literacy among university students Journal of Public Mental Health 10:198-210

Gorbanev I et al. (2018) A systematic review of serious games in medical education: quality of evidence and pedagogical strategy Medical education online 23:1438718 doi: $10.1080 / 10872981.2018 .1438718$

Graafland M, Schraagen JM, Schijven MP (2012) Systematic review of serious games for medical education and surgical skills training Br J Surg 99:1322-1330 doi: 10.1002/bjs.8819

Hamari J, Malik A, Koski J, Johri A (2019) Uses and Gratifications of Pokémon Go: Why do People Play Mobile Location-Based Augmented Reality Games? International Journal of Human-Computer Interaction 35:804-819 doi: 10.1080/10447318.2018.1497115

Ibáñez M-B, Delgado-Kloos C (2018) Augmented reality for STEM learning: A systematic review Computers \& Education 123:109-123 doi: https://doi.org/10.1016/j.compedu.2018.05.002

Ivanitskaya L, O'Boyle I, Casey AM (2006) Health information literacy and competencies of information age students: results from the interactive online Research Readiness SelfAssessment (RRSA) J Med Internet Res 8:e6 doi: 10.2196/jmir.8.2.e6

Jensen L, Konradsen F (2018) A review of the use of virtual reality head-mounted displays in education and training Education and Information Technologies 23:1515-1529 doi: $10.1007 / \mathrm{s} 10639-017-9676-0$

Klímová B (2018) Mobile Learning in Medical Education Journal of Medical Systems 42:194 doi: 10.1007/s10916-018-1056-9

Krathwohl DR (2002) A revision of Bloom's taxonomy: An overview Theory into practice $41: 212-218$

Kuehn BM (2018) Virtual and Augmented Reality Put a Twist on Medical Education JAMA 319:756-758 doi: 10.1001/jama.2017.20800

Lindau ST, Tomori C, Lyons T, Langseth L, Bennett CL, Garcia P (2002) The association of health literacy with cervical cancer prevention knowledge and health behaviors in a multiethnic cohort of women Am J Obstet Gynecol 186:938-943

McMenamin PG, Quayle MR, McHenry CR, Adams JW (2014) The production of anatomical teaching resources using three-dimensional (3D) printing technology Anat Sci Educ 7:479486 doi: 10.1002/ase.1475 
Mills KA (2010) A Review of the "Digital Turn" in the New Literacy Studies Review of Educational Research 80:246-271 doi: 10.3102/0034654310364401

Moro C, Edwards L, Chess-Williams R (2016) 5-HT2A receptor enhancement of contractile activity of the porcine urothelium and lamina propria International journal of urology : official journal of the Japanese Urological Association 23:946-951 doi: 10.1111/iju.13172

Moro C, McLean M (2017) Supporting Students' Transition to University and Problem-Based Learning Medical Science Educator 27:353-361 doi: 10.1007/s40670-017-0384-6

Moro C, Mills KA (2019) Technology and learning in the classroom: six tips to get the balance right. The Conversation Media Group Ltd, Australia

Moro C, Spooner A, McLean M (2019) How prepared are students for the various transitions in their medical studies? An Australian university pilot study

MedEdPublish 8:25 doi: https://doi.org/10.15694/mep.2019.000025.1

Moro C, Stromberga Z, Raikos A, Stirling A (2017a) The effectiveness of virtual and augmented reality in health sciences and medical anatomy Anatomical sciences education 10:549-559 doi: 10.1002/ase. 1696

Moro C, Stromberga Z, Stirling A (2017b) Virtualisation devices for student learning: Comparison between desktop-based (Oculus Rift) and mobile-based (Gear VR) virtual reality in medical and health science education 201733 doi: 10.14742/ajet.3840

Murad MH, Coto-Yglesias F, Varkey P, Prokop LJ, Murad AL (2010) The effectiveness of self-directed learning in health professions education: a systematic review Medical Education 44:1057-1068 doi: 10.1111/j.1365-2923.2010.03750.x

Ng CL, Liu X, Chee SC, Ngo RY (2015) An Innovative 3-dimensional Model of the Epitympanum for Teaching of Middle Ear Anatomy Otolaryngol Head Neck Surg 153:832837 doi: 10.1177/0194599815584600

Nicholson DT, Chalk C, Funnell WR, Daniel SJ (2006) Can virtual reality improve anatomy education? A randomised controlled study of a computer-generated three-dimensional anatomical ear model Med Educ 40:1081-1087 doi: 10.1111/j.1365-2929.2006.02611.x

Nutbeam D (2000) Health literacy as a public health goal: a challenge for contemporary health education and communication strategies into the 21st century Health Promotion International 15:259-267 doi: https://doi.org/10.1093/heapro/15.3.259

Pamuk E, Mukuc D, Heck K, Reuben C, Lochner K (1998) Socioeconomic Status and Health Chartbook. National Center for Health Statistics, Hyattsville, Maryland 
Pimmer C, Mateescu M, Gröhbiel U (2016) Mobile and ubiquitous learning in higher education settings. A systematic review of empirical studies Computers in Human Behavior 63:490501 doi: 10.1016/j.chb.2016.05.057

Smith ML, Jones JFX (2018) Dual-extrusion 3D printing of anatomical models for education Anat Sci Educ 11:65-72 doi: 10.1002/ase.1730

Stromberga Z, Chess-Williams R, Moro C (2019) Histamine modulation of urinary bladder urothelium, lamina propria and detrusor contractile activity via $\mathrm{H} 1$ and $\mathrm{H} 2$ receptors Scientific Reports 9:3899 doi: 10.1038/s41598-019-40384-1

Taut D, Pintea S, Roovers JWR, Mananas MA, Baban A (2017) Play seriously: Effectiveness of serious games and their features in motor rehabilitation. A meta-analysis NeuroRehabilitation 41:105-118 doi: 10.3233/nre-171462

tom Dieck MC, Jung T (2018) A theoretical model of mobile augmented reality acceptance in urban heritage tourism Current Issues in Tourism 21:154-174 doi: $10.1080 / 13683500.2015 .1070801$

Triepels CPR, Smeets CFA, Notten KJB, Kruitwagen RFPM, Futterer JJ, Vergeldt TFM, Van Kuijk SMJ (2019) Does three-dimensional anatomy improve student understanding? Clinical Anatomy 0 doi: 10.1002/ca.23405

Unsworth L (2001) Teaching Multiliteracies Across the Curriculum vol 6.

van der Heide I, Rademakers J, Schipper M, Droomers M, Sorensen K, Uiters E (2013) Health literacy of Dutch adults: a cross sectional survey BMC Public Health 13:179 doi: 10.1186/1471-2458-13-179

Wang R, DeMaria S, Jr., Goldberg A, Katz D (2016) A Systematic Review of Serious Games in Training Health Care Professionals Simulation in healthcare : journal of the Society for Simulation in Healthcare 11:41-51 doi: 10.1097/sih.0000000000000118

Wynter L, Burgess A, Kalman E, Heron JE, Bleasel J (2019) Medical students: what educational resources are they using? BMC Med Educ 19:36 doi: 10.1186/s12909-019$1462-9$ 